\title{
Razonabilidad y responsabilidad: Rawls, Kant y la Teoría del Derecho Contractual
}

\author{
Martín Hevia*
}

Resumen: En este trabajo me centraré en algunas de las ideas expuestas en Reasonableness and Responsibility: A Theory of Contract Law, donde presento una teoría del derecho contractual que pretende completar la idea de Rawls en el sentido de entender las interacciones contractuales como interacciones razonables, esto es, interacciones basadas en términos públicos e interpersonales de interacción. Por otro lado, para completar la obra de Rawls, hago uso de la teoría jurídica contractual que Kant desarrolló en La Metafisica de la Moral y que muchos filósofos del derecho han estudiado recientemente para explicar las doctrinas fundamentales del derecho contractual.

Palabras clave: derecho contractual, justicia distributiva, responsabilidad.

Abstract: In this paper I focus on some ideas exposed in Reasonableness
and Responsibility: A Theory of Contract Law, where I present a theory
of contractual law that pretends to complete Rawls' theory by
understanding contractual interactions as reasonable interactions, that
is, interactions based on public and interpersonal terms of interaction.
On the other hand, to complete Rawls' work, I use the contractual
theory of law that Kant developed in The Metaphysics of Morals, that

* Escuela de Derecho, Universidad Torcuato Di Tella. Email: mhevia@utdt.edu. Este artículo está basado en una serie de artículos, publicados antes y después de la publicación del libro. Ver "Justicia Distributiva, Justicia Correctiva y Derecho Contractual", en Teoría y Crítica del Derecho Civil y Comercial, compilado por Martín Hevia. México D. F.: Ediciones Fontamara, 2012. 
Martín Hevia

has been recently studied by many law philosophers in order to explain the main doctrines of contractual law.

Key words: contractual law, distributive justice, responsibility.

\section{Introducción}

Reasonableness and Responsibility: A Theory of Contract Law (Dordrecht: Springer Law \& Philosophy Library, 2012) presenta una teoría del derecho contractual. El punto de partida del libro es una pregunta: si, como sostiene John Rawls, la justicia es la virtud fundamental de las instituciones sociales, ¿cómo debemos entender el derecho contractual? Mi respuesta es que la justicia requiere que entendamos las reglas contractuales en función de la idea de "términos de interacción justos". La idea subyacente es la de reciprocidad, es decir, la idea de que es injusto que las personas puedan establecer unilateralmente las condiciones de interacción con los demás. Ello, a su vez, requiere concebir a las partes de un contrato como personas libres e iguales que consienten vincularse bajo condiciones que no se imponen unilateralmente.

El libro está inspirado en las ideas de John Rawls y de Immanuel Kant. Por un lado, presenta un enfoque rawlsiano del derecho contractual. John Rawls es uno de los filósofos políticos más influyentes de los últimos tiempos. Este estaba principalmente preocupado por lo que llama "la estructura constitucional esencial", es decir, no buscaba una justificación para el uso de la coerción para hacer ejecutables los acuerdos entre los individuos. Tal vez es por eso que no se concentró en los principios que animarían al derecho privado ${ }^{1}$. En Reasonableness

1 En mi contra, podría señalarse que algunos pasajes de $A$ Theory Of Justice están dedicados a explicar la institución de la promesa. Rawls explica que "[p]rometer es una acción definida por un sistema público de reglas" que son como las "reglas de los juegos". Los filósofos morales pueden explicar por qué, si alguien toma ventaja de una institución justa, aquel deberá cumplir con sus reglas. Desde esta visión, la razón por la cual debemos mantener nuestras promesas es que la institución social de la promesa es valiosa para la sociedad. Si no cumplimos con nuestras promesas, hacemos algo inco- 
and Responsibility, tomo su idea de una división de responsabilidad entre la sociedad y los individuos para ofrecer un enfoque normativo rawlsiano del derecho contractual. En el modelo de la división de responsabilidad, la justicia requiere que usemos la coerción solo para hacer cumplir los términos justos de interacción. Por ello, mi argumento es que las interacciones contractuales son interacciones razonables, esto es, interacciones basadas en términos públicos e interpersonales de interacción. En algún sentido, entonces, el libro es un intento de completar la obra de Rawls. Por otro lado, para completarla, hago uso de la teoría jurídica contractual que Kant desarrolló en La Metafisica de la Moral y que muchos filósofos del derecho han estudiado recientemente para explicar las doctrinas fundamentales del derecho contractual ${ }^{3}$. El libro, también, utiliza como ejemplo las teorías del derecho contractual de la tradición del common law, aunque sugeriré que también explican las doctrinas fundamentales de la tradición continental europea - de

rrecto, a saber, socavamos una práctica socialmente valiosa. Ver Rawls, J., $A$ Theory Of Justice, Cambridge: Harvard University Press, 1999, págs. 344-48. En el capítulo 8 de Reasonableness and Responsibility, al discutir Contract as a Promise. A Theory of Contractual Obligation de Charles Fried (Cambridge, Mass.: Harvard University Press, 1981) explico por qué el enfoque basado en las promesas no nos ayuda a entender el derecho contractual.

En Justice as Fairness: A Restatement, Rawls menciona que no discutirá los problemas de lo que él llama "justicia local". Presumiblemente, los principios y reglas del derecho contractual formarían parte de la justicia local. Ver Justice as Fairness: A Restatement. Cambridge: Harvard University Press, 2001, pág. 11.

2 Kant, I., The Metaphysics of Morals, trad. de Mary Gregor. Cambridge: Cambridge University Press, 1996.

3 Es plausible explicar el interés de los filósofos del derecho por desarrollar teorías de este tipo como consecuencia de una reacción de filósofos del derecho provenientes de jurisdicciones de common law al auge del análisis económico del derecho - que justifica y/o explica las instituciones jurídicas apelando al criterio de maximización de la utilidad-. Desde la década de 1970, entonces, los filósofos del derecho han tomado las ideas de Aristóteles, Hegel y Kant, en particular, la idea de autonomía, para desarrollar teorías de diferentes ramas del derecho -incluyendo al derecho privado- . Ver Spector, H., "Fairness versus Welfare from a Comparative Law Perspective", Chicago-Kent Law Review 79, 2004, pág. 525. 
Martín Hevia

hecho, en este artículo, usaré ideas de Reasonableness and Responsibility para explicar algunas doctrinas de esta última tradición-.

El libro tiene 10 capítulos, pero en este artículo me concentraré en los siete primeros. El artículo está organizado del siguiente modo. La sección 1 sitúa la teoría que propongo en el contexto de la filosofía política. Primero, introduzco la visión de quienes creen que el derecho contractual debe diseñarse de modo tal que promueva la justicia distributiva. Luego, explico la visión de los libertarios, que sostienen que el derecho contractual es la institución principal de nuestra sociedad y que la redistribución viola derechos. Finalmente, explico los defectos de ambas posiciones. Mis críticas son la puerta de entrada a la sección 2 , en la que introduzco la "división de la responsabilidad" y explico la distinción entre "deberes relacionales" y "deberes no relacionales". Explico que la división de la responsabilidad presupone, a su vez, una concepción de la "persona razonable", es decir, un sujeto capaz de desarrollar planes propios y de actuar en conformidad con principios de justicia públicos. En la sección 3, conecto la división de la responsabilidad, la idea de persona razonable y los deberes relacionales con la teoría del derecho privado de Kant. Allí explico la distinción entre personas y cosas y los diferentes modos en que las personas razonables pueden interactuar. Uno de ellos es intercambiando bienes y servicios a través de contratos. La sección 4 discute tres preguntas desde la perspectiva desarrollada en las secciones anteriores: ¿qué puede ser objeto de un contrato? ¿Cuáles son las acciones por incumplimiento contractual? ¿Qué criterios determinan cuándo se ha celebrado un contrato? Finalmente, en la sección V, ofrezco una conclusión.

\section{II.Filosofía política y Teoría del Derecho Contractual (capítulos 2, 3 y 4)}

En esta sección sitúo la teoría propuesta en Reasonableness and Responsibility en el contexto de las discusiones de filosofía política sobre el fundamento del derecho contractual, en particular, la distinción entre lo que llamo posiciones "monistas" y posiciones "dualistas". El dualismo sostiene que los principios prácticos aplicables al diseño 
institucional, por un lado, y los principios prácticos aplicables a la conducta individual de las personas, por el otro, deben ser principios diferentes. El monismo, en cambio, niega dicha tesis. Por ejemplo, para un monista como Liam Murphy, Rawls es dualista porque, según Rawls, hay una "división del trabajo" entre los principios de justicia que rigen el diseño de las instituciones sociales y aquellos que los individuos deben seguir en sus conductas particulares. El monismo rechaza esta idea y sostiene que los principios de justicia que los individuos deben poner en práctica en sus conductas son los mismos que deben usarse para diseñar las instituciones sociales. En el libro me concentro en dos posiciones monistas. En primer lugar, discuto la posición que sostiene que todas las cuestiones de justicia sean cuestiones de justicia distributiva - me referiré a esta posición como el "enfoque distributivista"- En segundo lugar, discuto la posición que sostiene que no existen cuestiones de justicia distributiva -identifico esta posición con el libertarismo de Robert Nozick-. Ambas posiciones se parecen al utilitarismo porque el utilitarismo utiliza el principio de utilidad para evaluar tanto las instituciones como las conductas personales - el utilitarismo establece que los individuos tenemos la obligación moral de maximizar la utilidad global en cada acción que realizamos- Si bien ni el distributivista ni el libertario necesariamente son utilitaristas, ambas posiciones aceptan una idea que los utilitaristas aceptarían, a saber,

El argumento general de que toda posición moral/política debe, al nivel fundamental, evaluar cuán justas son las instituciones en función de principios normativos que también se aplican a las decisiones de los individuos ${ }^{4}$.

En un extremo del espectro ideológico está el enfoque distributivista. Un ejemplo de este enfoque es la posición que Liam Murphy adopta en "Institutions and the Demands of Justice". En tal ensayo, Murphy sostiene que

4 Murphy, L., "Institutions and the Demands of Justice" Philosophy \& Public Affairs 27, 1998, pág. 251. 
Martín Hevia

no deberíamos pensar a las instituciones jurídicas, políticas y a otras instituciones sociales como si constituyeran dominios normativos separados que requieren principios normativos fundacionales diferentes sino fundamentalmente como los medios que las personas utilizan para cumplir con sus objetivos morales colectivos ${ }^{5}$.

Murphy sostiene que, si los individuos estuviesen capacitados para poner en práctica en su vida cotidiana los principios morales que suscriben, entonces tendrían una obligación de hacerlo. El problema es que, en realidad, los individuos no pueden imaginar o contemplar todas las consecuencias distributivas de cada curso de acción que deciden realizar. Para Murphy, solo una vez que tomamos conciencia del hecho de que somos "malos calculadores de consecuencias" podemos entender por qué diseñamos instituciones que son más eficaces para hacer el trabajo de asegurar que haya justicia en un modo más sistemático. Por ello, la división del trabajo entre instituciones e individuos es la segunda mejor opción. Murphy sostiene que

Una división del trabajo que deja en manos de la justicia de fondo la tarea de asegurarse de que haya una distribución justa en la sociedad y que hace responsable a las personas solamente por un conjunto de obligaciones negativas nos permitiría comer nuestra torta y también preservarla. Cumpliríamos con nuestros objetivos igualitarios sin hacer que nuestra vida sea miserable en el proceso ${ }^{6}$.

Según el enfoque distributivista, no es del todo claro si realmente debemos tener una institución que sea como aquello que llamamos derecho contractual. Nuestra decisión de tener o de no tener derecho contractual dependerá de información empírica contingente acerca de cuál es el mejor modo de cumplir con nuestros objetivos distributivos. En caso de que consideráramos necesario tener derecho de los

5 Murphy, op. cit., pág. 253. Thomas Nagel tiene una posición similar. Ver Equality and Partiality. Oxford: Oxford University Press, 1991.

${ }^{6}$ Murphy, op. cit., pág. 258. 
contratos, tendríamos que diseñar sus reglas de un modo tal que, en última instancia, estas promuevan nuestra concepción de la justicia distributiva. Por supuesto, este enfoque asume que los principios que se aplican a la conducta del Estado son los mismos que rigen las transacciones privadas. También podría ocurrir que los principios sean diferentes, pero ello sería así simplemente en virtud de una cuestión de "competencia institucional" — por ejemplo, tal como mencioné antes, porque somos malos calculando los efectos distributivos que nuestras decisiones pueden tener y, por ello, preferimos aliviar a los individuos de la carga de tener que hacerlo y dejamos los problemas de justicia distributiva en manos del Estado-. El punto central de Murphy puede resumirse del siguiente modo: para él, no existen los contratos genuinamente privados porque, en el fondo, cualquier contrato es un modo de promover la justicia distributiva.

En la literatura filosófica más específica sobre el derecho contractual, Anthony Kronman adopta un enfoque distributivista en su ensayo seminal, "Contract Law and Distributive Justice"7. Los juristas generalmente sostienen que el principio de autonomía personal es el que justifica la existencia del derecho contractual. Todos parecen estar de acuerdo en la naturaleza voluntaria de los contratos. La posición de Kronman es llamativa porque sostiene que la voluntariedad de los contratos debe entenderse completamente en función de la justicia distributiva. Para Kronman, todos los aspectos esenciales de los contratos deben justificarse en función de la justicia distributiva. Dado que sostiene que el derecho de los contratos debe entenderse de este modo, Kronman adopta la posición monista y comparte con Murphy la idea de que la división del trabajo solo puede estar fundada en cuestiones pragmáticas.

En el lado opuesto del espectro ideológico, es decir, en la posición de aquellos que niegan que la justicia requiera poner en práctica alguna concepción de la igualdad distributiva, se encuentran Robert Nozick y otros libertarios. Ellos también rechazan la idea de que hay principios especiales para el diseño institucional, aunque la rechazan

7 Yale Law Journal 89 (1980). 
por razones que no son las mismas que las de Murphy. Los libertarios entienden todas las cuestiones de justicia como cuestiones de justicia correctiva. Según creen, el estado no es diferente de cualquier otra asociación privada: para los libertarios, los poderes y las obligaciones que tiene el Estado no pueden ser diferentes de los poderes que los individuos poseían antes de que el Estado existiese. Una organización como el Estado es legítima solo en la medida en que sea consecuencia de acuerdos voluntarios entre personas que consienten crear una institución de ese tipo en la que "tercerizan", por decirlo de un modo gráfico, la provisión de ciertos servicios que necesitan, tales como seguridad y tribunales para dirimir controversias entre las personas.

En términos generales, los libertarios creen que hay una presunción prima facie en contra de cualquier interferencia con la libertad de los individuos. Ello quiere decir que, a menos que haya consentimiento, la redistribución de la propiedad de unos a otros es impermisible. El cobro de impuestos con fines redistributivos, por ejemplo, es una redistribución ilegítima de recursos. Todavía más, los libertarios creen que no hay algo así como la justicia (re)distributiva porque todas las cuestiones de justicia tienen que ver con las relaciones interpersonales.

Finalmente, Nozick también sostiene que un defecto central de las teorías de la justicia distributiva igualitarias (a las que llama teorías "pautadas" o "de estado final") es que, si bien se comprometen con la libertad, para mantener el patrón de igualdad, tienen que restringirla: una vez que se deja a las personas utilizar sus recursos como más lo prefieran, la distribución resulta irremediablemente alterada. En consecuencia, para mantener vigente un principio de justicia pautado o de estado final se requieren continuas interferencias a la libertad de las personas, tales como prohibirles transferir sus recursos a otros.

La teoría de Nozick es una teoría de "justicia procedimental pura": dada la existencia de reglas procedimentales justas, cualquiera sea el resultado de la aplicación de las reglas, este será justo. Así, para Nozick, si las personas transfieren voluntariamente sus derechos de propiedad a otras personas, el resultado de esa transferencia será un estado de cosas justo - sin que importe que, como resultado de la acumulación de transferencias, algunos tengan mucho más y otros 
mucho menos-. Las teorías pautadas, en cambio, son teorías de "justicia procedimental perfecta", es decir, teorías que cuentan con un criterio que determina qué resultados son justos y un procedimiento diseñado para garantizar que se satisfaga el criterio de justicia.

Si pensamos en el libertarismo de este modo, el contraste con la posición de Murphy se aclara más: mientras que para Murphy, realmente, los contratos no tienen nada de privado, los libertarios piensan que, en definitiva, todas las instituciones son esencialmente privadas.

Ahora bien, en los capítulos 3 y 4 del libro explico por qué tanto los distributivistas como los libertarios están equivocados. En primer lugar, sostengo que los distributivistas como Kronman no pueden explicar el sentido en el que los contratos son interacciones entre individuos que privadamente ejercen su libertad para intercambiar bienes y servicios: las interacciones contractuales son excusas para promover la justicia distributiva. Si hubiera una manera mejor de hacerlo, entonces no tendríamos derecho contractual. Los acuerdos entre las personas, así como también la responsabilidad por incumplimiento, son meras herramientas que pueden o no ser útiles para promover la justicia distributiva ${ }^{8}$. En el capítulo 4 explico que, a diferencia de los distributivistas, dado el énfasis que hacen en la idea de libertad, los libertarios sí pueden explicar por qué los contratos son interacciones privadas. También tienen razón cuando sostienen que, en principio, los individuos deben tener libertad para interactuar intercambiando bienes y servicios. Sin embargo, cometen el error de pensar que tienen el monopolio de la idea de que "justicia procedimental pura". A partir

8 Quizá, Kronman podría presentar su posición de un modo diferente, por ejemplo, basándose en alguna forma de utilitarismo de reglas. Sin embargo, debido a las objeciones presentadas por diversos autores, el utilitarismo de reglas enfrenta problemas serios: si las reglas que adoptamos son meras reglas de buen cubero, entonces, debería estar permitido hacer excepciones. Cuantas más excepciones hacemos, el utilitarismo de reglas más se acerca al de actos. Esta objeción podría no funcionar contra interpretaciones más complejas del utilitarismo como la de David Brink. Ver Brink, D., Moral Realism and the Foundations of Ethics. Nueva York: Cambridge University Press, 1989. No discutiré aquí esta posibilidad, que la contemplo en Reasonableness and Responsibility. 
del capítulo 5, desarrollo la teoría de la justicia de Rawls, una teoría de la "justicia procedimental pura" que no requiere interferencias constantes en la libertad de las personas. Según explicaré en la sección siguiente, para Rawls la justicia requiere que las personas tengan acceso a determinados bienes. Sin embargo, una vez que las personas los tienen y que siguen las reglas de la cooperación justa, la distribución que resulte será justa. Veamos.

\section{La división de la responsabilidad y el Derecho Contractual (capítulo 5)}

El punto de partida de la teoría de la justicia de John Rawls es la idea de una "sociedad bien ordenada". En ella, en primer lugar, las personas aceptan y saben que todos los demás aceptan la misma concepción política de la justicia (aunque no necesariamente deben compartir una concepción comprehensiva del bien, por ejemplo, pueden tener diferencias políticas o pertenecer a diferentes religiones). Ello significa que todos aceptan los mismos principios públicos de justicia. En segundo lugar, las principales instituciones políticas y sociales de una sociedad bien ordenada están organizadas de acuerdo a esos principios públicos de justicia, independientemente de cuáles sean. Finalmente, los ciudadanos entienden y ponen en práctica esos principios públicos de justicia9 .

La sociedad bien ordenada incluye lo que Rawls llama una "división de la responsabilidad". En "Unidad social y Bienes Primarios", Rawls explica esta idea del siguiente modo:

La sociedad, los ciudadanos como un cuerpo colectivo, aceptan la responsabilidad de mantener la igualdad de las libertades fundamentales y la igualdad de oportunidades justas mientras los ciudadanos (como individuos)... aceptan la responsabilidad de revisar y ajustar sus fines y aspiraciones en vista de todos los medios que sirven para perseguir fines que puedan esperar, dada su situación presente y previsible. Esta división

9 Rawls, Justice as Fairness. A Restatement. Cambridge, Mass.: The Belknap Press of The Harvard University Press, 2001, pág. 9. 
de responsabilidad confía en la capacidad de las personas de asumir la responsabilidad respecto de sus fines y moderar los reclamos que realizan ante sus instituciones sociales de conformidad con el uso de bienes primarios. Los reclamos de los ciudadanos frente a las libertades, oportunidades, y todos los medios necesarios para perseguir fines están protegidos de las demandas irrazonables de los demás ${ }^{10}$.

Este pasaje sugiere la existencia de dos dimensiones de la división de la responsabilidad. La primera dimensión de la división de la responsabilidad es su dimensión pública, que da lugar a determinados tipos de deberes. En primer lugar, las personas tienen el deber de apoyar instituciones justas. Es un deber que tienen con la sociedad en general, y no con alguien en particular. Estos deberes son, entonces, deberes "no relacionales". Al mismo tiempo, la sociedad tiene el deber de asegurar que las personas tengan la oportunidad de llevar una vida que consideren exitosa: los individuos deben tener aquellos recursos y oportunidades que les permitan establecer y perseguir sus planes. Rawls se refiere a esos medios como "bienes primarios", que son medios que sirven para perseguir cualquier fin. En este marco, el contenido específico de los planes que adopta cada persona es irrelevante: mientras no interfieran con las elecciones de otros, las personas deben ser libres de hacer lo que crean adecuado ${ }^{11}$.

${ }^{10}$ John Rawls, "Social Unity and Primary Goods", Utilitarianism and Beyond, editado por Amartya Sen y Bernard Williams. Cambridge: Cambridge University Press, 1982, pág. 170.

${ }^{11}$ Ripstein, A., "Private Order and Public Justice: Kant and Rawls", Virginia Law Review 92, 2006, pág. 1391. T. M. Scanlon explica la división de responsabilidad del siguiente modo: "La idea es la siguiente. La "estructura básica" de la sociedad es su sistema legal, político y económico, cuya función es definir las posiciones en que los diferentes poderes y los beneficios económicos se adjuntan. Si una estructura básica hace esto de un modo aceptable - si los ciudadanos no tienen quejas razonables respecto de su acceso a distintas posiciones dentro de este esquema o al paquete de derechos, libertades, y oportunidades frente a recompensas económicas que presentan ciertas posiciones en particular- entonces la estructura es justa. Corresponde a las personas, operando dentro de este esquema, elegir sus 
La división de la responsabilidad incluye otra dimensión, que puede explicarse en términos de las responsabilidades entre personas. Los individuos deben tomar responsabilidad por aquello que hacen con sus propias vidas. Dado que las personas son libres para perseguir sus propios fines, solo pueden hacerlo en la medida en que permitan a otras perseguir sus propios planes al mismo tiempo. Esta es una idea de igual libertad: si mi vida es mi responsabilidad, entonces otros no deberían interferir en ella. Pero, al mismo tiempo, no debería desplazar los costos de mis actividades a otros: debo hacerme responsable de mi propia vida, y ellos deben hacerse responsables de la suya - pero no por mis hechos ${ }^{12}$ —. Esta segunda dimensión da nacimiento a "deberes relacionales" entre las personas.

Las diferentes dimensiones de esta división de la responsabilidad reflejan una concepción normativa de la persona, que presupone que los individuos tienen los dos siguientes poderes morales ${ }^{13}$ :

a. Una capacidad para desarrollar una concepción del bien: capacidad de formar, revisar y perseguir racionalmente una concepción de lo bueno. Esta capacidad está asociada con la racionalidad instrumental, es decir, con el homo economicus: las personas racionales elijen los medios más efectivos para perseguir sus

propios fines y hacer uso de las oportunidades dadas y recursos para perseguir esos fines lo mejor que puedan. El éxito o el fracaso, la felicidad o la infelicidad será un resultado de su propia responsabilidad".

Ver Scanlon, T. M., What We Owe to Each Other. Cambridge, Mass: Harvard University Press, 1998, pág. 244.

${ }^{12}$ Noten que, hasta ahora, solo hice referencia a planes de vida de los individuos. Ello no significa que tales planes sean necesariamente individualistas: las personas pueden elegir perseguir sus planes afiliándose a diferentes grupos y asociaciones. Ver Rawls, J., "Fairness to Goodness", en John Rawls: Collected Papers, editado por Samuel Freeman. Cambridge: Harvard University Press, 1999, pág. 273.

${ }^{13}$ Estos dos poderes deben ser complementados con lo que Rawls llama "poderes de la razón". Estos poderes son aquellos del juicio, el pensamiento y de la inferencia. Son poderes que son esenciales a los dos poderes y requeridos para su ejercicio. Rawls, J., Political Liberalism. Nueva York: Columbia University Press, 1993, pág. 19. 
planes, cualesquiera sean. El modo en que las personas forman sus preferencias, o si estas son buenas o malas — desde alguna concepción del bien es-, desde esta perspectiva, irrelevante. Este poder, a su vez, conlleva la capacidad de revisar su concepción de lo bueno en la medida en que lo consideren necesario ${ }^{14}$.

b. Una capacidad de desarrollar un sentido de justicia: capacidad de entender, de poner en práctica y de actuar motivado por -y no solo de conformidad con- los principios de justicia política que especifican los términos justos de cooperación social. Por ello, Rawls sostiene que, además de ser racionales, las personas son razonables: están dispuestas a actuar sobre la base de un principio que otros puedan aceptar - y que por lo tanto, puedan encontrarlo justificable-.

Lo razonable tiene un carácter público que lo racional no tiene. Como explica Rawls, "la razonabilidad lleva a los agentes al mundo de los otros, donde se convierten en iguales, listos para proponer o

${ }^{14}$ Rawls se refiere a la capacidad y no a su realización. Esto significa que incluso si, como una cuestión de hecho, la capacidad no se desarrolla, todos los seres son tomados como poseedores de esta capacidad y, en consecuencia, con el derecho a reclamar su parte justa de sus instituciones sociales y políticas. Además, algunas personas pueden tener una mayor capacidad para el sentido de justicia - les puede resultar más fácil aplicar los principios de justicia - pero esa mayor capacidad es "un activo natural como cualquier otra habilidad".

También es importante notar que incluso si las personas cambian su concepción del bien, su identidad pública o legal como personas libres no se ve afectada por esos cambios. La gente puede cambiar su afiliación política o religiosa. Por ejemplo, como dice Rawls, "[e]n ruta a Damasco Saúl de Tarso se convierte en Pablo el Apóstol". Sin embargo, sus derechos y deberes básicos no se ven afectados. Además, incluso si cambian de religión o inclinación política, están facultados para hacer los mismos reclamos que podían hacer antes de que esos cambios tuvieran lugar. Ver John Rawls, Justice as Fairness. A Restatement. Cambridge, Mass.: The Belknap Press of The Harvard University Press, 2001, pág. 23. 
aceptar términos justos de interacción"15. Estos términos de interacción justa son términos que los agentes comparten y reconocen públicamente frente a otros. Así, las personas razonables se ven con el derecho a presentar reclamos en sus instituciones sociales para que puedan seguir su propia concepción de lo bueno, pero también reconocen el derecho de los demás a hacer lo mismo ${ }^{16}$.

Lo racional y lo razonable se muestran en ambas dimensiones de la división de la responsabilidad. Cada persona es responsable de su vida, pero para que todos podamos perseguir nuestros planes al mismo tiempo se requieren límites recíprocos a nuestra libertad. Si usted y yo decidimos interactuar, nuestra interacción debe ser completamente voluntaria. No es aceptable que alguien use a otro para perseguir sus planes sin haber obtenido su consentimiento, y viceversa; no puedo hacer uso de sus bienes sin su autorización ni imponerle costos que usted no haya consentido. Para garantizar que esto sea así es necesario contar con un sistema de reglas que establezcan límites recíprocos a la libertad que el Estado haga valer. Este sistema se refleja en las categorías fundamentales del derecho privado, del derecho romano y del derecho civil y el common law. Veamos.

\section{Deberes relacionales y la teoría kantiana del derecho privado (capítulo 6)}

He argumentado que las personas racionales tienen sus propios fines que perseguir. Las personas están interesadas en tener recursos y oportunidades precisamente porque pueden establecer y perseguir

${ }^{15}$ Rawls, Political Liberalism. Nueva York: Columbia University Press, 1993, pág. 53.

${ }^{16}$ Ibídem. En cambio, las personas irrazonables son oportunistas: "pueden planear participar en planes de cooperación, pero no están dispuestos a honrar, o incluso a proponer, con excepción de una necesaria pretensión pública, ningún principio general o normas para especificar los términos justos de interacción. Están dispuestos a violar los términos que se adapten a sus intereses cuando las circunstancias lo permitan" Rawls, Political Liberalism. Nueva York: Columbia University Press, 1993, pág. 50. 
las diferentes concepciones de lo bueno que puedan adoptar. Por eso, deben ser capaces de hacer lo que quieran con sus vidas bajo los requerimientos de igual libertad: no tendría sentido darles recursos y luego no permitirles que dispongan de ellos de acuerdo a sus planes. Tomé estas ideas de la división de responsabilidad de Rawls. Sin embargo, Rawls no desarrolló una teoría del derecho privado; más bien, se concentró en la organización institucional más básica, es decir, en los lineamientos que debe seguir una constitución. Pero las ideas de Rawls tienen continuidad con las de Kant, que sí desarrolló una teoría del derecho privado. Por empezar, como explica Ripstein, los dos poderes morales que introduje antes son parte de lo que Kant llama el "derecho innato de humanidad" sobre uno mismo17. La capacidad para desarrollar una concepción del bien propia es equivalente a la noción de "independencia" de Kant: cada uno de nosotros, y no los demás, determina qué planes adoptará. La capacidad para desarrollar un sentido de lo justo es la capacidad para reconocer los derechos de los demás, así como la de hacer valer los derechos propios. Esta noción de "independencia" es el punto de partida de la teoría del derecho privado que Kant desarrolló en La Metafísica de la Moral, en la sección llamada "Doctrina del Derecho". Veámosla con más detalle.

Para empezar, la independencia no es una característica de los agentes aislados, sino que es una idea relacional: A es independiente de $\mathrm{B}$ en la medida en que no esté sujeto a las decisiones de B. Así, si una persona fuera el único habitante del mundo, si tuviera a su alcance un conjunto de acciones valiosas para hacer, e incluso si pudiera realizarlas, no tendría sentido decir que esa persona es "autónoma". Tampoco es una idea aplicable universalmente: no todo ente puede ser autónomo. La independencia presupone la distinción entre personas y cosas. Para Kant, las personas tienen una capacidad para determinar cuáles son sus propios planes. Las cosas, en cambio, son meramente

${ }^{17}$ Ripstein, A., "Private Order and Public Justice: Kant and Rawls", Virginia Law Review 92, 2006, pág. 1399. 
medios para perseguir esos objetivos. Por eso, es habitual que los filósofos morales sostengan que "las personas son fines en sí mismos".

Para que las personas puedan establecer sus propios planes necesitan de medios. Los medios incluyen el dominio sobre el cuerpo propio, que tenemos en virtud del mero hecho de ser personas: no es necesario que hagamos nada para tener derecho a usar nuestro cuerpo. Los poderes externos, a los que Kant llama "cosas", son los medios que tenemos para perseguir los planes que podemos adoptar en virtud de nuestra condición de personas. Decir que una persona es dueña de ciertos medios es decir que las cosas que posee están sujetas a su decisión.

Las personas independientes son las que pueden determinar a qué fines afectar los medios que poseen. Esta idea de independencia es la que lleva a que Kant rechace la esclavitud: el esclavo depende completamente de las decisiones de su amo, que no tiene la obligación de justificar sus decisiones ante su esclavo.

Dada la distinción entre personas y cosas, la pregunta que surge es:

Cómo una pluralidad de personas separadas, con fines separados, puede ser libre de perseguir sus planes al máximo, cualesquiera sean, en la medida en que sean compatibles con la libertad de las demás personas de ejercer la misma libertad. La persecución de planes separados, a su vez, requiere de límites recíprocos a la libertad que reflejan las maneras diferentes en las que interactúan las personas. Para que los límites sean recíprocos, deben obligar a todos del mismo modo, es decir, deben concordar con una ley universa ${ }^{18}$.

La distinción entre personas y cosas lleva a la idea de que hay tres modos en que las personas pueden interactuar y, al mismo tiempo, tres modos en que se puede interferir con la capacidad de las personas para perseguir sus planes. Cada una de estas interferencias dará lugar a una reacción del derecho. Esas reacciones estarán justificadas porque la idea de límites recíprocos a la libertad implica que es permisible restringirla para protegerla. Así, si al perseguir mis planes,

${ }^{18}$ Ripstein, A., "Authority and Coercion", Philosophy. \& Public Affairs 32, 2004, pág. 10. 
violo sus derechos, lo privo de su derecho a usar sus medios para fines con los que usted concuerde (al violar sus derechos uso sus medios sin su consentimiento). En consecuencia, para Kant, está justificado restringir mi libertad para obligarme a que lo deje en situación de ser el amo de sus medios nuevamente.

Los modos posibles de interacción entre personas son los siguientes ${ }^{19}$ :

1. Podemos perseguir nuestros planes de modo independiente, lo que requiere de derechos de las personas y de propiedad. Veamos. Los derechos de propiedad son derechos a tener a disposición las cosas para poder establecer y perseguir los planes de vida propios. Dado que las cosas son necesarias para establecer y determinar planes de vida propios, deben ser protegidas. Así surge la idea de derechos de propiedad, es decir, el poder de controlar las cosas propias y de excluir a los demás de su uso si así lo queremos. En consecuencia, si alguien interfiere con mi propiedad, por ejemplo, si usa mis cosas sin pedirme permiso, viola mis derechos, es decir, me priva de mi poder de decisión sobre mis cosas. El derecho de la responsabilidad extracontractual y el enriquecimiento sin causa (o unjust enrichment en la terminología del common law) son el reflejo de la responsabilidad que surge como consecuencia de las relaciones entre personas que persiguen sus planes de manera independiente. E1 derecho de la responsabilidad extracontractual se ocupa de los casos en los que una persona daña a la persona o la propiedad de otra sin el consentimiento de esta última. En esos casos, obliga al demandado a indemnizar al demandante por los daños que le haya causado. A su vez, el enriquecimiento sin causa existe cuando una persona se queda con la propiedad de otra sin el consentimiento de aquella.

${ }^{19}$ Para una discusión excelente de la clasificación de las obligaciones en la obra de Kant, ver Weinrib, J., "What Can Kant Teach Us About Legal Classification?", Canadian Journal of Law \& Jurisprudence 23, 2010, págs. 203-231. Tomo la descripción de los tres modos posibles de interacción de Ripstein, A., "Kant on Law and Justice", The Blackwell Guide to Kant's Ethics, editado por Thomas E. Hill Jr. Oxford: Wiley-Blackwell, 2009. 
Martín Hevia

2. Una persona puede actuar en nombre de otra, lo que da lugar a reglas jurídicas sobre status. En las relaciones fiduciarias, las personas actúan de un modo interdependiente, pero no consensualmente. Este tipo de interacción da lugar a relaciones que son similares a los derechos sobre las cosas: son relaciones de status en virtud de las que una persona puede actuar y tomar decisiones en nombre de la otra. En estos escenarios, los intereses del beneficiario dependen de las decisiones del fiduciario. El fiduciante no tiene capacidad para consentir o estar en desacuerdo con las decisiones que toma el fiduciario; es un límite estructural de este tipo de relaciones. Pero el fiduciario tiene la obligación de promover los intereses del fiduciante, es decir, no puede hacer lo que se le antoje. El ejemplo fundamental de este tipo de relaciones es la de la relación entre padres (o tutores, según el caso) e hijos menores de edad. Los padres deben actuar de modos que promuevan los intereses de sus hijos. Es decir, los padres no pueden tratar a sus hijos como meros medios para promover sus fines; los hijos no son cosas, aunque la incapacidad estructural para consentir hace que los padres tengan esta relación fiduciaria con sus hijos.

3. Finalmente, podemos perseguir nuestros planes conjuntamente de un modo voluntario, intercambiando bienes o servicios o haciendo donaciones. Ello requiere un sistema de derecho contractual. También, las personas deben ser capaces de transferir los derechos antes de la entrega efectiva de la cosa o antes de que el servicio en cuestión se realice. Eso les permitirá planificar con antelación. El derecho contractual es un modo de hacer todo esto: es un modo de subordinar nuestros bienes a nuestra propia concepción del bien ${ }^{20}$.

Cuando la gente celebra contratos coopera en proyectos particulares, de manera que cada persona pone sus competencias a disposición de otros. Esta es una característica importante de la idea rawlsiana de "establecer y perseguir" una concepción de lo bueno. El hecho de que las personas puedan tener la conducta futura de otras a su disposición es otra forma de permitirles establecer sus propios

${ }^{20}$ Arthur Ripstein, "Private Order and Public Justice: Kant and Rawls", Virginia Law Review 92, 2006, pág. 1838. 
objetivos. Visto de esta manera, la posibilidad de celebrar contratos aumenta su capacidad para alcanzar los objetivos que se fijaron. Al mismo tiempo, cuando las personas persiguen sus propios planes de este modo, la idea de igual libertad requiere que cumplan los términos de sus acuerdos. Si no lo hicieran, no estarían tomando responsabilidad por su propia vida. Además, si A incumple un contrato que tiene con $\mathrm{B}$ y no se exige que pague un costo por su incumplimiento, A estaría estableciendo los términos de la relación contractual unilateralmente porque estaría privando a $\mathrm{B}$ de algo a lo que este tiene derecho - esto es, el cumplimiento de A- La sección siguiente se concentra en la teoría kantiana del derecho contractual.

\section{E1 Derecho Contractual}

\section{V.1. ¿Qué puede ser objeto de un contrato? (capítulo 6)}

Según Kant, con la excepción de las personas independientes, todo puede ser objeto de un derecho adquirido. Por consiguiente, las acciones de otras personas también pueden adquirirse. Podemos transferirnos contractualmente el uso de determinados poderes. Esto da lugar a los derechos oponibles a otras personas, propios del derecho contractual. Los contratos generan derechos y obligaciones correlativas. Así, al momento de la formación del contrato, y antes del cumplimiento de la obligación, el acreedor adquiere del deudor la posesión de algo, pero no de algo material: el acreedor obtiene un crédito contra el deudor. El contenido de tal crédito es el cumplimiento de la obligación del deudor, esto es, un hecho (o una omisión, según el caso) del deudor. La obligación de cumplir con el contrato es una obligación de darle al demandante algo a lo que tiene derecho, a saber, el cumplimiento del deudor tal como está especificado en los términos del acuerdo entre el deudor y el acreedor.

Esto no quiere decir que, al momento de la celebración del contrato, el acreedor se convierta en dueño del deudor (como si este fuera esclavo del acreedor), sino que el acreedor tiene un derecho para exigirle al deudor que cumpla con su obligación de entregar el 
bien prometido o de cumplir con el servicio prometido, dependiendo del contenido del contrato que hayan celebrado. Kant lo explica del siguiente modo:

Mediante un contrato adquiero algo externo. Pero, ¿qué es lo que adquiero? Puesto que se trata simplemente de la causalidad de la decisión de otro en relación al acto que me prometió, lo que adquiero directamente por un contrato no es una cosa externa sino su acción mediante la que la cosa queda en mi control de modo tal que la hago mía. Por un contrato, entonces, adquiero la promesa del otro (pero no lo que me prometió) y aun así algo se agrega a mis pertenencias externas; me enriquecí (locupletior) al adquirir una obligación activa sobre la libertad y los medios de otro ${ }^{21}$.

El acreedor, entonces, adquiere del deudor lo que el derecho llama un derecho in personam, esto es, un derecho que un individuo puede hacer valer frente a una persona en particular que, a su vez, tiene la obligación correlativa de cumplir con su obligación.

La dimensión transaccional de los contratos explica el tipo de derecho que el acreedor adquiere contra su deudor. En los términos del derecho, el acreedor tiene un derecho in personam oponible a su deudor. Como mencioné anteriormente, estos derechos son derechos que una persona puede oponer a otra persona en particular, y no al resto del mundo; en cambio, los derechos reales, o derecho in rem, son oponibles erga omnes. Por supuesto, los derechos reales pueden tener origen transaccional, es decir, pueden adquirirse mediante la interacción entre personas; por ejemplo, cuando usted me transfiere la propiedad de un bien de su propiedad. Pero el derecho real subsecuente es oponible erga omnes, es decir, es oponible incluso a aquellos que no participaron de

${ }^{21}$ Ver Kant, op. cit., 6:723. Son las normas de la libertad las que requieren que sea posible poseer la acción de otro. Si el hecho de que yo posea la posibilidad de exigirle que haga algo es compatible con su libertad, con la mía y con la de todos los demás, entonces ello tiene que estar jurídicamente permitido. Para este punto, ver: Byrd, S. y Hrushka, J., "Kant on 'Why Must I Keep My Promise'”, Chicago Kent Law Review 81, 2006, págs. 47-58. 
nuestra transacción. En cambio, el derecho personal solamente puede adquirirse de la persona ante quien puede oponerse.

Es importante resaltar que en los contratos que obligan al deudor a la entrega de un bien, dado que el acreedor adquiere un derecho personal oponible a su deudor, este no adquiere la propiedad del bien en cuestión. Este hecho nos lleva a la pregunta: si no es al momento de la celebración del contrato, ¿cuándo es que el acreedor se convierte en el dueño del bien prometido? Esta pregunta surge respecto de los contratos en los que la entrega del bien no tiene lugar al momento de la celebración del acuerdo. Pensemos en el ejemplo de la compraventa de un caballo, diferida en el tiempo. Kant sostiene que, antes de la entrega del caballo, si las partes no se ponen de acuerdo acerca de quién debe tener la posesión del caballo y el comprador lo deja en manos del vendedor, el primero no es el dueño del caballo ${ }^{22}$. E1 comprador se convierte en su dueño solamente después de que tenga el caballo en su posesión y realice un acto independiente de la celebración del contrato que establezca el derecho in rem sobre el caballo. Tanto en la tradición continental como en la del common law estos actos llevan el nombre de "actos posesorios".

En la mayoría de los contratos que no son de cumplimiento inmediato, las partes se pondrán de acuerdo respecto de la fecha en la que la entrega del bien debe tener lugar. Antes de la entrega del bien, dado que el comprador no es todavía dueño del bien, es el vendedor, y no el comprador, quien debe hacerse cargo si se materializa cualquier daño que sufra el bien en cuestión. Ello es así en virtud de que el acreedor solamente tiene un derecho a exigir que el deudor cumpla con su obligación de poner al acreedor en la posición en la que puede obtener la posesión del caballo ${ }^{23}$. Ahora, si las partes se ponen de acuerdo respecto de una fecha en la que el acreedor debe buscar el caballo para obtener la posesión y este no se hace presente, se justifica que el

${ }^{22}$ Para una discusión de este punto, ver Benson, P., "The Basis for Excluding Liability for Economic Loss in Tort Law", en Philosophical Foundations of Tort Law, editado por David G. Owen. Oxford: Oxford University Press, 1995, págs. 455-456.

${ }^{23}$ Kant, op. cit., 6:275. 
Martín Hevia

deudor transfiera al acreedor cualquier riesgo que podría enfrentar el bien en cuestión.

\section{V.2. ¿Cuáles son las acciones en caso de incumplimiento? (capítulo 6)}

En el common law, la acción estándar por incumplimiento contractual es la indemnización por las expectativas frustradas (expectation damages), es decir, una indemnización que tiene por objetivo dejar al demandante en la misma situación en la que estaría si el demandado hubiese cumplido con el contrato. Ahora bien, si una vez que celebramos un contrato, el acreedor es dueño de una acción del deudor y si, según Kant, dicha acción es un medio del acreedor, ¿cómo se explica el hecho de que el acreedor no tenga derecho al cumplimiento específico y forzoso de la obligación? ${ }^{24} \mathrm{Si}$ la libertad no exige cumplimiento específico, ¿qué exige?

Una respuesta posible es que, si bien idealmente los acreedores tienen derecho al cumplimiento específico de la obligación, una vez que el deudor incumplió, se torna imposible cumplir con la obligación tal como había sido pactada originalmente. Como explica Smith, "por definición, lo que prometió hacer para un tiempo en particular ya no se puede hacer... lo mejor que el deudor puede hacer es actuar de un modo similar al de la obligación original" 25 .

Otra posible respuesta podría asociarse con la sugerencia de Holmes: "La obligación de cumplir con un contrato significa... que... usted debe pagar daños y perjuicios en caso de que lo incumpla - y nada más que eso-_"26. Otro modo posible de entender las obligaciones contractuales es de modo tal que sean promesas "disyuntivas"

${ }^{24}$ Tomo este punto y la pregunta de Hodgson, L-P., "Collective Action and Contract Rights", Legal Theory 17, 2011, págs. 209-226.

${ }^{25}$ Smith, S.A., Contract Theory. Oxford: Oxford University Press, 2004, pág. 54.

${ }^{26}$ Wendell Holmes, O., "The Path of the Law", Harvard Law Review 10, 1897, pág. 462. 
de o bien cumplir con lo prometido, o bien pagar una indemnización por los daños y perjuicios ${ }^{27}$.

De acuerdo con esta segunda posibilidad, en verdad, la indemnización no sería consecuencia del incumplimiento porque las partes del contrato originalmente habían acordado que el deudor podía elegir pagar los daños, en lugar de cumplir específicamente. En algunos casos, podría ser cierto que las partes entendieron que su contrato era una promesa disyuntiva. Sin embargo, no es el modo en que habitualmente las partes consideran los contratos que celebran. Por consiguiente, estas explicaciones no son satisfactorias porque no capturan la naturaleza pública del lenguaje del derecho contractual ${ }^{28}$.

Veamos qué explicación podría ofrecer el teórico kantiano. Hodgson lo explica del siguiente modo:

Si la justificación última de los derechos contractuales es la libertad, entonces el objetivo del derecho al conceder la indemnización debe ser asegurar que la libertad de la víctima del incumplimiento no esté amenazada por el incumplimiento. La compensación, entonces, solo será adecuada en la medida en que sea equivalente al cumplimiento como medio con el que la víctima puede perseguir su plan. En otras palabras, para determinar qué califica como compensación adecuada, debemos preguntar qué pondrá a la víctima en la posición que habría tenido, con respecto a la persecución de sus planes, si el deudor hubiese cumplido el contrato. En circunstancias normales, ello exige que la compensación se base en el valor de mercado del cumplimiento esperado. Una visión de los derechos contractuales basada en la libertad requiere que la acción estándar sea la indemnización por la frustración de las expectativas $^{29}$.

${ }^{27}$ Gold, A. S., "A Property Theory of Contract", Northwestern University Law Review 103, 2009, pág. 54.

${ }^{28}$ Smith, op. cit., pág. 54.

${ }^{29}$ Hodgson, op. cit., págs. 224-225. 
Como explica Hodgson, la provisión "con respecto a la persecución de sus planes" tiene un rol fundamental en el argumento. Los demandantes no tienen un derecho a sentirse tan contentos o satisfechos como se sentirían si el deudor hubiese cumplido con el contrato ${ }^{30}$. $\mathrm{Su}$ derecho es a tener a su disposición nuevamente los medios. La felicidad o satisfacción, como tales, no son medios para que las personas establezcan y persigan sus planes. Del mismo modo, en la responsabilidad extracontractual, si alguien meramente hace infeliz al lector, pero no lo daña físicamente o no daña su propiedad, usted no tiene derecho a ser compensado ${ }^{31}$ (probablemente, este es el caso con lo comentaristas de este artículo).

Es importante mencionar, también, que el teórico kantiano tiene en sus manos una explicación del alcance de la indemnización por responsabilidad por incumplimiento. El incumplimiento de nuestro contrato lo priva a usted de algo que le pertenece. Al incumplir el

${ }^{30}$ Hodgson, op. cit., págs. 224-225.

${ }^{31}$ Tomo este punto de Ripstein, A., "As It Had Never Happened", William \& Mary Law Review 48, 2007, pág. 1984.

Andrew Gold propone una explicación diferente: "En los casos contractuales en los que el deudor decide no cumplir a pesar de haber transferido un interés de propiedad en el cumplimiento de la promesa, el incumplimiento infringe los derechos del acreedor. Ello implica cometer daño y la justicia correctiva requiere que se rectifique la pérdida que sufre el acreedor. Sin embargo, a la luz del rol que la autonomía tiene en la circunscripción del interés del acreedor en el cumplimiento, el incumplimiento es una violación permisible del derecho de propiedad del deudor." Gold, op. cit., nota 24, págs. 57-58. Gold agrega que "el pago de la indemnización es un ejercicio de justicia correctiva dentro de los límites establecidos por el valor de la autonomía. Puede que sea injusto que el deudor no reconozca el derecho de propiedad del acreedor al cumplimiento, pero sería más injusto todavía no reconocer el valor de la autonomía del deudor." No creo que sea necesario recurrir a la idea de violaciones permisibles al derecho de propiedad porque, si los derechos contractuales son medios, el acreedor víctima del incumplimiento tiene derecho a los medios de los que el deudor lo priva al incumplir. Según creo, la indemnización por las expectativas frustradas no es una compensación por la infracción a un derecho de propiedad cuyo contenido es el cumplimiento; la indemnización, más bien, devuelve al acreedor los medios que debería tener a su disposición. Gold, op. cit., pág. 58. 
contrato, lo estoy privando no solamente de sus medios, sino también de los usos posibles que usted habría dado a sus medios. Si bien no tiene a su disposición los usos posibles que habría dado a sus medios con la misma certeza que tiene los medios en cuestión (no tiene necesariamente certeza del uso que podría darle a los medios), de todos modos, tiene derecho a que se lo compense por la pérdida de los usos posibles de esos medios (con mi incumplimiento, usted ya no tiene la posibilidad de usarlos en el mismo sentido en que la tenía antes del incumplimiento ${ }^{32}$. Sin embargo, no cualquier destino que usted podría haberle dado a sus medios cuenta por igual. Para determinar el alcance de la responsabilidad del deudor por el incumplimiento, y si esta alcanza a los daños que en el common law llevan el nombre de consequential damages, debemos mirar al momento de la celebración del acuerdo. De acuerdo con la doctrina del famoso Hadley v. Baxendale, que mencioné en la primera sección de este artículo, es necesario determinar si, al momento de la celebración, es razonable asumir que las partes podían o debían haber contemplado el uso que el acreedor le daría a lo adeudado. Consideremos ahora otro ejemplo del common law, el caso Security Stove \& Mfg. Co. v. American Railway Express Co ${ }^{33}$. En el caso citado, un fabricante de estufas esperaba un modelo nuevo de estufas que tenía que ser enviado por barco a una feria de comercio. En la feria, el fabricante esperaba obtener clientes nuevos. El fabricante había invertido en la feria; por ejemplo, el presidente de la fábrica y sus empleados habían viajado para estar presentes en la feria. El problema fue que no tuvieron nada para mostrar allí: como la empresa encargada de enviar la estufa incumplió con su obligación, el fabricante perdió la chance de intentar ganar clientes nuevos. Por supuesto, era imposible saber con certeza cuánto dinero habría ganado el fabricante si hubiese podido mostrar en la convención el producto en cuestión. Sin embargo, había certeza respecto del uso que el fabricante le iba a

${ }^{32}$ Ver Ripstein, A., Force and Freedom. Kant's Legal and Political Philosophy. Cambridge: Harvard University Press, 2009, pág. 21.

33227 Mo. App. 175, 51 S.W. 2D 572 (1932). 
Martín Hevia

dar al bien: su intención era utilizarlo para atraer clientes nuevos, que podrían ser fuente de ganancias en el futuro.

En resumen, la indemnización por los daños causados por la frustración de expectativas redime el derecho del acreedor al cumplimiento de la obligación porque le da al acreedor los medios a los que este tenía derecho en virtud del contrato.

\section{V.3. Razonabilidad y formación de los contratos (capítulo 7)}

Hasta ahora, he echado mano de la teoría del derecho contractual de Kant. Ahora bien, Kant no explica qué criterios deben utilizarse para determinar si se ha celebrado un contrato entre dos - o máspersonas. Sin embargo, algunas de sus ideas de Doctrina del Derecho pueden ser útiles para explicar cómo puede determinarse cuándo se ha celebrado un contrato. Kant sostiene que al derecho le concierne solamente lo que él llama "el principio universal del derecho", o la coexistencia de la libertad de todos de acuerdo con la ley universal. Según Kant,

[e]1 concepto de derecho... tiene que ver... con la relación externa... de una persona con otra, en la medida en que sus acciones, como hechos, puedan tener influencia (directa o indirecta) en cada una de ellas ${ }^{34}$.

En este pasaje, Kant invitaba a pensar el derecho como independiente de la virtud. El derecho solo debería ocuparse de lo que los individuos hacen o dicen (en algunos casos, también, de lo que no hacen cuando tienen la obligación de actuar), más allá de si los motivos para actuar de una forma $u$ otra sean los correctos (sin perjuicio de que los motivos sean relevantes en el ámbito de la filosofía moral). ¿Cómo se refleja ello en el derecho contractual? Veamos. Una visión posible de los contratos es que estos involucran un "encuentro de las mentes" de las partes, es decir, la idea de que, para que se celebre un contrato, los contratantes deberían coincidir en aquello que tienen en mente. Si 
no fuera así, obligar a una persona a que cumpla con aquello a lo que no quiso comprometerse sería una imposición inaceptable. Así, las teorías "subjetivistas" de los contratos sostienen que los contratos se forman sobre la base de lo que las partes realmente quisieron hacer, es decir, lo que tenían en mente al contratar. En cambio, en Reasonableness and Responsibility defiendo una concepción objetiva de la formación de los contratos. En esta concepción, el examen para determinar si se celebró o no un contrato se basa en lo que una persona razonable hubiera querido decir por cada cosa que las partes dijeron o hicieron. Es más, sostengo que una sociedad en donde las interacciones entre individuos están gobernadas por condiciones justas de interacción requiere un examen objetivo para determinar si se han creado obligaciones vinculantes y exigibles. Veamos.

Dado que los contratos crean obligaciones vinculantes y exigibles para las partes, tienen que ser consistentes con su igual libertad, esto es, tienen que ser consistentes con otros individuos con derechos en un sistema de igual libertad. En el modelo de la división de responsabilidad, el uso de la coerción solo está justificado cuando es compatible con un sistema de igual libertad. Para ilustrar el punto, consideremos una analogía con el derecho de daños. En el derecho de daños, la adopción de un estándar subjetivo favorecería a los demandados porque, como defensa, un infractor podría alegar algo así como "no quise hacer eso" o "no sabía que estaba haciendo eso". Esto implicaría la aplicación de términos unilaterales de acción, incompatibles con la igual libertad: los demandados estarían imponiendo los términos de interacción al demandante. En un contrato, la situación es diferente. Presumiblemente, cada una de las partes en el contrato tiene una comprensión propia, subjetiva, del acuerdo. Si es así, entonces, un estándar subjetivo no es realmente una opción disponible: en un contrato, habría dos subjetividades compitiendo. Pero si el derecho hace cumplir el deseo de una de las partes por sobre el de la otra, estaría imponiendo términos unilaterales de interacción, que permiten a la parte cuyo deseo prevalece dominar aquel de la otra parte. El uso de la coerción para cumplir tal contrato, entonces, sería incompatible con un sistema de igual libertad. 
Martín Hevia

Los contratos involucran a dos o más partes que consienten. En este modelo, el consentimiento tiene una naturaleza pública. Tratar a las partes como iguales implica que adoptemos estándares públicos. Desde una aproximación objetiva, los pensamientos "internos" de las partes no son definitivos para determinar la existencia o el contenido de un contrato. Este estándar objetivo para la formación del contrato está atado a la noción de lo razonable, que mencioné al introducir la concepción de la persona. El estándar apropiado para la formación del contrato es un estándar de comportamiento que resulta justo para los individuos en interacción con otros. Así, si una persona acepta una oferta mediante la firma de un contrato, pero en secreto piensa que no ha consentido al contrato, entonces, contra lo que pueda pensar, ha consentido. Del mismo modo, la persona que rechaza una oferta, digamos, diciendo "no" a la otra parte, y, mentalmente, piensa que ha consentido, no lo ha hecho. Este será siempre el caso a menos que ambas partes sepan que, cuando el oferente dice "sín", significa "no", y cuando dice "no", realmente quiere decir "estoy de acuerdo".

Este enfoque de las personas es familiar para los abogados: es lo que en el common law se conoce como el estándar de la persona razonable.

Oliver Wendell Holmes Jr. es famoso —entre otras muchas razones - porque promovió este estándar en el derecho privado, que ejemplificó con responsabilidad en el derecho de daños. Para Holmes, el estándar es el estándar objetivo de los vecinos razonables:

Si... un hombre nace torpe y apresurado, si siempre tiene accidentes y se lastima o lastima a sus vecinos, no hay duda de que sus defectos congénitos estarán permitidos en los tribunales del Cielo, pero sus golpes y caídas no serán menos problemáticos para sus vecinos que si surgen de su negligencia culpable. Sus vecinos le exigen en consecuencia, a su propio riesgo, que se acerque a su estándar, y los tribunales que los vecinos establecen se oponen a tomar en cuenta la ecuación personal de riesgo de dicho individuo ${ }^{35}$. 
Es importante mencionar que, si bien defiendo un enfoque objetivo del derecho de los contratos, no todos los sistemas legales están pensados desde un enfoque similar. Por ejemplo, los juristas franceses generalmente sostienen que el derecho privado francés es mucho más subjetivo que el del common law. Los tratados franceses de contratos dicen que la base de las obligaciones contractuales es la autonomía de la voluntad. Para los juristas franceses, solo importa la voluntad interna y subjetiva del individuo - la volonté psychologique ("voluntad psicológica") - . Este papel fundamental de la noción de autonomía como fundamento de las obligaciones legales voluntarias es, posiblemente, un producto del individualismo económico y filosófico del siglo XIX ${ }^{36}$. Según creo, la gran mayoría de los tribunales de los sistemas jurídicos de tradición continental, que siguen la tradición francesa, utilizan un discurso jurídico que los acerca a esta tradición. Sin embargo, si bien el enfoque de los juristas franceses es subjetivo, los tribunales franceses $y$, en general, las jurisdicciones que siguen la tradición continental hacen uso de la concepción objetiva. Por ejemplo, cuando discuten cuestiones de formación de contratos, esto es, si hay una escisión entre las declaraciones de las partes y sus intenciones subjetivas, los tribunales franceses tienden a no mirar las intenciones subjetivas: adoptan argumentos de construcción de la voluntad de las partes. En la doctrina del error, un entendimiento subjetivo de los contratos usualmente libera a la parte equivocada: la voluntad subjetiva de la parte equivocada prevalece sobre su declaración externa y objetiva. Por el contrario, un enfoque objetivo del derecho contractual ataría a la parte equivocada a sus obligaciones: su declaración externa prevalecería por sobre su voluntad subjetiva. En la práctica, cuando los tribunales franceses analizan si un determinado error de

${ }^{36}$ Tomé esta idea de Valcke, C., "Comparative Law as Comparative Jurisprudence. Objectivity and Subjectivity in The English, French, and German Law of Contractual Mistake" (Trabajo presentado al Special Workshop on Ethics, Economics and the Law en el XXII Congreso Munidal de Filosofía del Derecho y Filosofía Social, Mayo de 2005) [Sin Publicar]. Para puntos similares, ver también Hauser, J., Objectivisme et Subjectivisme Dans L'Acte Juridique. París: Librairie Générale de Droit et de Jurisprudence, 1971. 
una de las partes vicia su consentimiento y, consecuentemente, anula el contrato, adoptan un enfoque objetivo: no cualquier error, por más sincero que sea, puede dar lugar a la nulidad de un acuerdo. Para que proceda la nulidad, el error debe ser excusable y debe estar relacionado con una característica del acuerdo que la otra parte sabía o debió saber que era determinante para la parte que comete el error. La inclusión de estas dos condiciones hace al enfoque francés de los contratos, al menos respecto de los errores, más objetivo que subjetivo: desde una visión subjetiva, solo importa la existencia del error y las circunstancias bajo las cuales el error nace son irrelevantes. Pero esto no es, sin embargo, lo que los tribunales franceses dicen ${ }^{37}$. Podría objetarse que, como han sostenido algunos juristas franceses, dada la dificultad de descubrir qué es lo que las partes quisieron hacer cuando actuaron de un determinado modo, o cuando dijeron algo, el estándar objetivo es solamente un "segundo mejor" 38 . Pero ello no es la razón por la que debería adoptarse un enfoque objetivo. Si los contratos son resultado de que dos o más partes se reúnen para lograr algo en común, ¿por qué debería prevalecer la voluntad de una de las partes por sobre la voluntad de la otra? No hay dudas de que el consentimiento es el aspecto central de un contrato, es decir, el consentimiento es la "causa fuente" de los contratos. La justificación para contratar es que se trata de una herramienta para los individuos que voluntariamente participan en cooperación con otros. El consentimiento, sin embargo, también es objetivo. Supongan que una de las partes en un acuerdo dijera que no quiso decir algo, o que no quiso hacer algo que hizo porque "pensó" que estaba haciendo otra cosa, o que no pudo imaginar que sus palabras serían entendidas del modo en el que la otra parte lo hizo. Si en estos casos, y meramente por estos pensamientos internos de la parte "equivocada", se garantiza el perdón, entonces no habría nada de malo en dejar que una de las partes en un contrato establezca los términos de interacción unilateralmente. Sin embargo,

37 Ibid.

38 Chabas, J., De la declaration de volonté en droit civil francaise 81-81, Syrey, 1931, citado en Valcke, supra nota 39. 
desde la perspectiva rawlsiana que adopto en este ensayo, permitir a una de las partes establecer los términos de interacción unilateralmente resulta irrazonable. Eso sería problemático porque dejaría a una de las partes totalmente a merced de los caprichos de la otra. A la luz de esto, en el modelo rawlsiano, el derecho privado se preocupa por lo que es apropiado como estándar de comportamiento con individuos en interacción con otros en lugar de lo que los individuos por separado consideran justo. Esto es así porque los estándares públicos reflejan la idea de que individuos iguales interactúan en términos de condiciones justas de interacción. Desde este punto de vista, por supuesto, el consentimiento importa, pero se lo entiende en términos públicos ${ }^{39}$.

\section{Conclusión}

Mi pregunta inicial - icómo debemos entender el derecho contractual?- da lugar a otras subpreguntas. En este artículo me dediqué a discutir algunas de esas preguntas, pero otras tantas quedan sin responder. Discuto algunas de ellas en los capítulos 8, 9 y 10 del libro - ¿qué distingue a un contrato de una mera promesa? ¿Por qué los terceros no pueden exigir el cumplimiento de un contrato, así como tampoco las partes pueden contratar para violar los derechos de los terceros? ¿Cuánta información deben revelarse las partes entre sí antes de celebrar un contrato?- En este artículo, sin embargo, mi intención ha sido presentar las bases de una teoría del derecho contractual inspirada en Rawls y en Kant. Espero que Reasonableness and Responsibility sea una contribución para enriquecer la comprensión del derecho contractual, una de las instituciones fundamentales de nuestra sociedad.

${ }^{39}$ En un artículo reciente, explico cómo el enfoque objetivo se utiliza para la interpretación contractual y para llenar lagunas en los contratos. Este análisis no es parte de Reasonableness and Responsibility, pero utiliza el mismo argumento. Ver Hevia, M., "¿Cómo deben completarse los contratos incompletos?: Un desafío a la tesis de Coleman", en: Papayannis, Diego M. (ed.). Derechos de daños, principios morales y justicia social. Madrid: Marcial Pons, 2013, págs. 153-165 
Martín Hevia

\section{Bibliografía}

Benson, P., "The Basis for Excluding Liability for Economic Loss in Tort Law", en Philosophical Foundations of Tort Law, David G. Owen (ed). Oxford: Oxford University Press, 1995.

Brink, D., Moral Realism and the Foundations of Ethics. Nueva York: Cambridge University Press, 1989.

Byrd, S. y Hrushka, J., "Kant on 'Why Must I Keep My Promise”, Chicago Kent Law Review 81, 2006.

Gold, A. S., "A Property Theory of Contract", Northwestern University Law Review 103, 2009.

Hauser, J., Objectivisme et Subjectivisme Dans L'Acte Juridique. París: Librairie Générale de Droit et de Jurisprudence, 1971.

Hevia, M., "¿Cómo deben completarse los contratos incompletos?: Un desafío a la tesis de Coleman", en: Papayannis, Diego M. (ed.). Derechos de daños, principios morales y justicia social. Madrid: Marcial Pons, 2013.

Hodgson, L-P., "Collective Action and Contract Rights", Legal Theory 17, 2011.

Holmes, O. W., The Common Law. Boston: Little Brown, 1963.

Kant, I., The Metaphysics of Morals, trad. de Mary Gregor. Cambridge: Cambridge University Press, 1996.

Murphy, L., "Institutions and the Demands of Justice" Philosophy \& Public Affairs 27, 1998, pág. 251.

Rawls, J., A Theory Of Justice, ed. Rev. Cambridge: Harvard University Press, 1999.

Rawls, J., "Fairness to Goodness", en John Rawls: Collected Papers, Samuel Freeman (ed). Cambridge: Harvard University Press, 1999. Rawls, J., Political Liberalism. Nueva York: Columbia University Press, 1993.

Rawls, Justice as Fairness: A Restatement. Cambridge: Harvard University Press, 2001.

Ripstein, A., "As It Had Never Happened", William \& Mary Law Review 48, 2007. 
Ripstein, A., "Authority and Coercion", Philosophy \& Public Affairs 32, 2004.

Ripstein, A., "Kant on Law and Justice", The Blackwell Guide to Kant's Ethics, Thomas E. Hill Jr (ed). Oxford: Wiley-Blackwell, 2009.

Ripstein, A., "Private Order and Public Justice: Kant and Rawls" Virginia Law Review 92, 2006, pág. 1391.

Ripstein, A., Force and Freedom - Kant's Legal and Political Philosophy. Cambridge: Harvard University Press, 2009.

Scanlon, T. M., What We Owe to Each Other. Cambridge, Mass: Harvard University Press, 1998.

Smith, S. A., Contract Theory. Oxford: Oxford University Press, 2004. Spector, H., "Fairness versus Welfare From a Comparative Law Perspective", Chicago-Kent Law Review 79, 2004.

Valcke, C., "Comparative Law as Comparative Jurisprudence Objectivity and Subjectivity in The English, French, and German Law of Contractual Mistake" [Sin Publicar].

Weinrib, J., "What Can Kant Teach Us About Legal Classification?", Canadian Journal of Law \& Jurisprudence 23, 2010.

Wendell Holmes, O., "The Path of the Law", Harvard Law Review 10, 1897. 